\title{
DIAGNÓSTICO DA MECANIZAÇÃO EM UMA REGIÃO PRODUTORA DE GRÃOS ${ }^{1}$
}

\section{LEANDRO M. GIMENEZ ${ }^{2}$, MARCOS MILAN ${ }^{3}$}

RESUMO: As máquinas agrícolas, depois da terra, representam o maior investimento para o agricultor, e sua adequação ao tamanho da propriedade é um fator fundamental na redução dos custos. Há, entretanto, no País, carência de informações que permitam a análise e a comparação sobre a eficiência do uso desses equipamentos. Com isso, o objetivo deste trabalho foi avaliar o estado da arte e realizar diagnóstico quanto à posse e uso de sistemas mecanizados em propriedades agrícolas. Para tanto, elaborou-se um questionário que foi aplicado a 139 propriedades de diferentes tamanhos na região dos Campos Gerais, Estado do Paraná, e na região sul do Estado de São Paulo. Essas propriedades foram divididas em estratos de 100-300 ha, 300-600 ha, 600-900 ha e acima de 900 ha. Os resultados mostram que os operadores não recebem suficiente treinamento, as propriedades maiores utilizam-se mais eficientemente das máquinas, a potência por área dos tratores nas menores áreas é o dobro das maiores e poucos fabricantes dominam o mercado na região.

PALAVRAS-CHAVE: mecanização agrícola, tratores, indicadores.

\section{FARM MACHINERY UTILIZATION IN A ROW-CROP PRODUCER REGION}

\begin{abstract}
Besides land, agriculture machinery represents the biggest investment for the farmer and its adjustment to the property size is a basic factor related to cost reduction. However, there is a lack of information that does not make possible the analysis and the comparison about the efficiency of these equipments. Therefore, the objective of this work is to evaluate how it is and perform a diagnosis concerning the ownership and use of mechanized systems in agricultural farms. A questionnaire was developed and applied to 139 properties of different sizes in the region of Campos Gerais, Parana State and in the south region of São Paulo State, Brazil. These properties were divided in areas of 100-300 ha, 300-600 ha, 600-900 ha and over 900 ha. The results show that the operators do not have enough training and the smaller farms have twice of tractor power per area than the bigger farms which use the machinery more efficiently. There are equipments producers that control the sales market in the region.
\end{abstract}

KEYWORDS: agricultural mechanization, tractors, indexes.

\section{INTRODUÇÃO}

A absorção de tecnologia exógena no projeto e a fabricação de equipamentos agrícolas associadas com o uso inadequado acarretaram problemas para a agricultura, como foi o caso da utilização indiscriminada de equipamentos como arados e grades no preparo do solo. O uso desses equipamentos trouxe profundos problemas de erosão do solo, ocasionando grandes danos, chegando a inviabilizar, em muitas regiões do País, o desenvolvimento da agricultura nos anos de 1970. A técnica do plantio direto foi uma das soluções para o problema de degradação dos solos, e essa técnica contou com a participação da indústria nacional de máquinas e das instituições de pesquisa agronômica para o seu desenvolvimento (BORGES FILHO, 2001).

Os sistemas mecanizados agrícolas, depois da terra, representam o maior investimento para uma propriedade agrícola, podendo atingir até $28 \%$ do custo de produção de soja no Paraná (CONAB, 2006). Segundo WITNEY (1988), encontrar o dimensionamento ótimo do sistema

\footnotetext{
${ }^{1}$ Extraído da dissertação de mestrado do primeiro autor.

${ }^{2}$ Engo Agrônomo, Mestrando em Máquinas Agrícolas, Departamento de Engenharia Rural, ESALQ/USP, Piracicaba - SP, lmgimenez@yahoo.com

${ }^{3}$ Prof. Adjunto, Departamento de Engenharia Rural, ESALQ/USP, Piracicaba - SP.

Recebido pelo Conselho Editorial em: 19-7-2006
}

Aprovado pelo Conselho Editorial em: 20-12-2006 
mecanizado para uma propriedade é tarefa difícil, pois as variáveis estão em constantes mudanças, e o que pode estar adequado para o momento, pode não ser ideal em curto prazo. Para VEIGA (2000), a quantidade de marcas e tipos de máquinas disponíveis no mercado e os custos indiretos associados à pontualidade das operações ("timeliness") tornam a seleção de sistemas mecanizados uma atividade complexa. EDWARDS (2001) ressalta que o ponto de mínimo custo do sistema mecanizado é determinado pela combinação de uma série de fatores relacionados com o tamanho dos equipamentos e com a pontualidade na realização das operações, devendo ser buscado continuamente pelo gestor do sistema mecanizado.

Utilizando uma abordagem descritiva, ANDRADE \& JENKINS (2002) realizaram estudo da dinâmica da mecanização presente em propriedades, em duas regiões produtivas no México, e não encontraram relações claras no estado da mecanização, havendo, entretanto, concordância de que deveria haver prioridade na elevação do índice de mecanização e que o tamanho da propriedade foi o fator com maior peso na introdução da mecanização.

SCHLOSSER et al. (2004) realizaram amostragem em que 87 propriedades foram analisadas, obtendo oito estratos. O índice de mecanização variou entre 7,82 e 1,96 kW ha ${ }^{-1}$, sendo menor para as propriedades com maior área agrícola, e a maior disponibilidade de potência nas propriedades de menor área demonstrou pior distribuição de investimentos, permitindo, entretanto, maior cuidado no trabalho e menor tempo para a realização das operações agrícolas.

Tendo como base a necessidade do uso de máquinas agrícolas para a produção de grãos, a participação das máquinas no custo total de produção, a relativa falta de informações que permitam comparação sobre a eficiência do seu emprego e a importância crescente do sistema de plantio direto para a produção agrícola, este trabalho teve como objetivo avaliar o estado da arte e realizar diagnóstico quanto à posse e ao uso de sistemas mecanizados em propriedades agrícolas de uma região produtora de grãos em sistema de plantio direto.

\section{MATERIAL E MÉTODOS}

O trabalho foi realizado na região dos Campos Gerais, centro-sul do Paraná e na região sul de São Paulo, entre os produtores de três cooperativas: Capal, Batavo e Castrolanda. A Capal localizase no município de Arapoti, a Batavo em Carambeí e a Castrolanda em Castro (Figura 1).

Obteve-se junto às cooperativas, com o apoio da Fundação $\mathrm{ABC}^{1}$, banco de dados dos produtores da região e áreas por eles cultivadas. Uma análise preliminar dos dados revelou que existia variação no tamanho das propriedades, optando-se por realizar amostragem estratificada de acordo com a área e com sua representatividade em termos de número de propriedades no total.

Foi utilizado um formulário padronizado com questões fechadas e organizadas em quatro itens principais: identificação, características do sistema de produção, recursos humanos e recursos mecanizados, totalizando 147 questões. Esse formulário foi aplicado por meio de telefonemas para os responsáveis pela administração das propriedades e, em alguns casos, foram realizadas visitas quando o volume de dados a ser coletado era elevado.

Do total de 441 propriedades com área cultivada superior a 100 ha existentes no banco de dados, foram selecionadas $139(31,5 \%)$. As propriedades foram divididas por estratos de áreas cultivadas, conforme apresentado na Tabela 1. O tamanho da menor unidade foi de 107 ha, e o maior foi de 1.932 ha, sendo o valor médio de 540,5 ha, totalizando 76.268 ha, com $62,9 \%$ de áreas próprias e $30,8 \%$ arrendadas. Os dados foram tabulados, processados e analisados, utilizando-se de planilha eletrônica.

\footnotetext{
${ }^{1}$ Fundação ABC - Fundação ABC para assistência e divulgação técnica agropecuária. Empresa privada que realiza pesquisas agropecuárias para os produtores das cooperativas Capal, Batavo e Castrolanda. www.fundacaoabc.org.br
} 


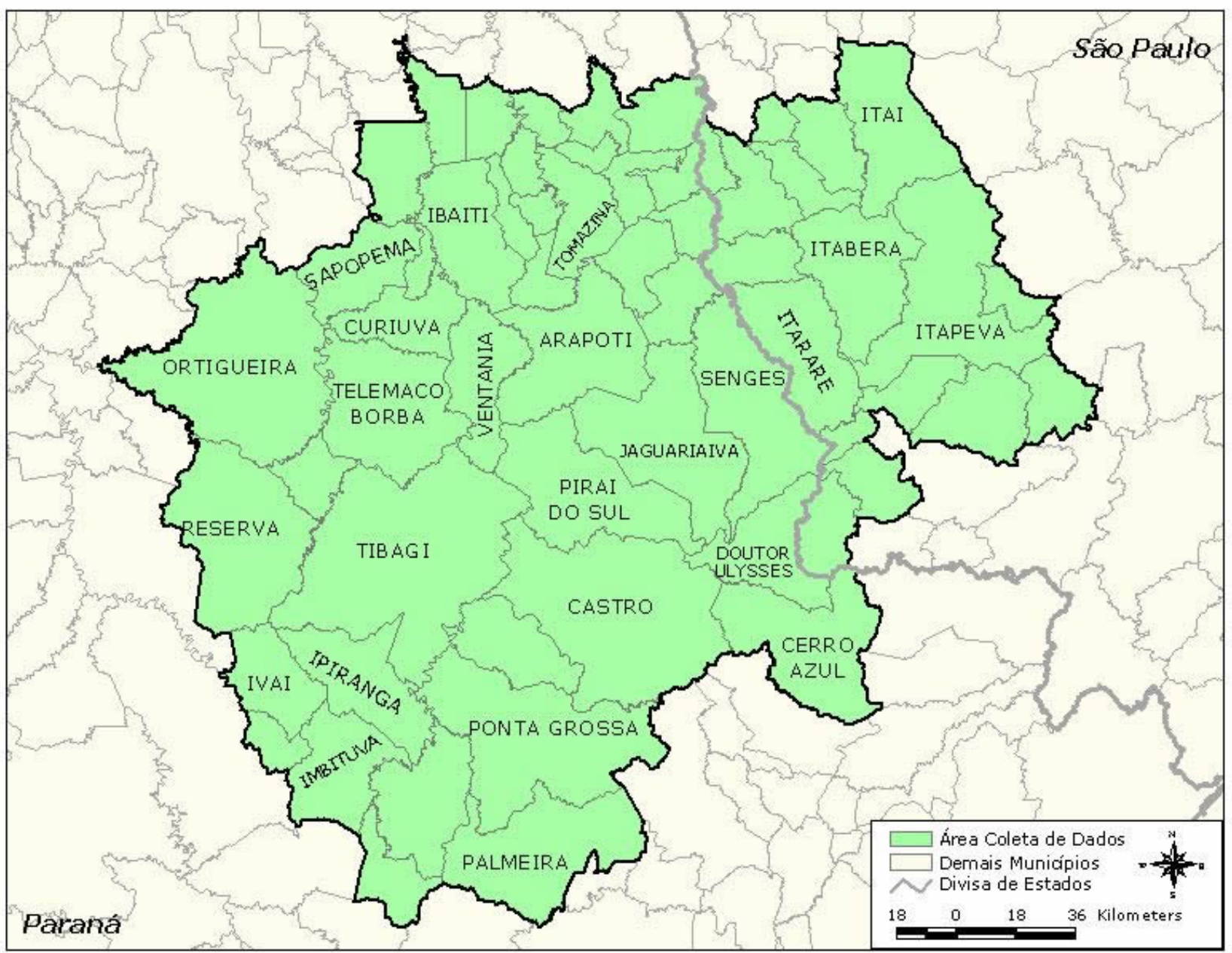

FIGURA 1. Região de coleta dos dados. (Fonte: Fundação ABC)

TABELA 1. Estratos, número de produtores e área média das unidades.

\begin{tabular}{crccc}
\hline \multirow{2}{*}{ Intervalo de Área (a) } & \multicolumn{3}{c}{ Produtores } & \multirow{2}{*}{ Área Média } \\
\cline { 2 - 4 } & Total & \multicolumn{2}{c}{ Entrevistados } & ha \\
ha & $\mathrm{n}^{\mathbf{0}}$ & $\mathrm{n}^{\mathbf{0}}$ & $\%$ & 203,6 \\
$100<\mathrm{a} \leq 300$ & 221 & 57 & 25,8 & 460,0 \\
$300<\mathrm{a} \leq 600$ & 126 & 39 & 30,9 & 745,6 \\
$600<\mathrm{a} \leq 900$ & 49 & 21 & 42,8 & $1.360,5$ \\
$\mathrm{a}>900$ & 45 & 22 & 48,8 & -- \\
\hline Total & 441 & 139 & -- & \\
\hline
\end{tabular}

\section{RESULTADOS E DISCUSSÃO}

A região onde o estudo foi desenvolvido, possui condições edafoclimáticas bastante favoráveis à produção do milho (Zea mays). Enquanto a média nacional de produtividade para essa cultura, nas safras de 2001 a 2003, foi de $3.395 \mathrm{Mg} \mathrm{ha}^{-1}$ (IBGE, 2006), a média das unidades nas últimas três safras (2003 a 2005), foi de $8.345 \mathrm{Mg} \mathrm{ha}^{-1}$. A cultura do trigo (Triticum aestivum) apresentou produtividade média de $2.962 \mathrm{Mg} \mathrm{ha}^{-1}, 52,5 \%$ superior à média nacional nas safras de 2001 a 2003, que foi de $1.942 \mathrm{Mg} \mathrm{ha}^{-1}$ (IBGE, 2006), mesmo estando a região sujeita a geadas freqüentes durante o ciclo dessa cultura. Para a soja (Glycine max), a média foi de $3.121 \mathrm{Mg} \mathrm{ha}^{-1}$, sendo $15,8 \%$ superior à média nacional de $2.696 \mathrm{Mg} \mathrm{ha}^{-1}$ nas safras de 2001 a 2003 (IBGE, 2006).

A participação das culturas na área foi semelhante entre os estratos, sendo na safra de verão, em média, $54,2 \%$ da área cultivada com soja e 34,6\% com milho. A cultura de feijão é cultivada em duas épocas, e a participação foi de $16,1 \%$. No inverno, $50,2 \%$ da área é cultivada com aveia- 
preta (Avena strigosa), utilizada como cultura de cobertura do solo, 31,5\% da área é semeada com trigo e o restante com outras culturas, como a aveia-branca (Avena sativa) e o azevém (Lolium multiflorum).

Com relação aos recursos humanos, o menor estrato utiliza um homem para cada 78,8 ha de área cultivada e, na medida em que a área aumenta, o número de homens necessários por área se reduz (Tabela 2). A participação da mão-de-obra terceirizada em relação ao total oscilou entre $8,6 \%$ e $13,4 \%$, não havendo tendência clara em função do tamanho do estrato.

TABELA 2. Recursos humanos utilizados nas unidades em função dos estratos.

\begin{tabular}{lcccc}
\hline \multirow{2}{*}{ Parâmetro } & \multicolumn{3}{c}{ Intervalo de Área (ha) } \\
\cline { 2 - 5 } & $100-300$ & $300-600$ & $600-900$ & $>900$ \\
\hline Número de funcionários & 2,3 & 4,3 & 6,6 & 10,7 \\
Número de operadores de máquinas agrícolas & 2,1 & 4,1 & 6,2 & 7,5 \\
Mão-de-obra terceirizada (homens/ano) & 0,3 & 0,5 & 0,7 & 0,8 \\
Área por trabalhador (ha) & 78,8 & 96,9 & 102,8 & 117,8 \\
\hline
\end{tabular}

Com relação à capacitação dos funcionários, em quase 55\% das vezes, os operadores nunca recebem treinamentos ou os recebem apenas quando uma nova máquina é adquirida.

Para os tratores, foram obtidas informações de 164 equipamentos no estrato de 100 - 300 ha, 171 entre 300 - 600 ha, 131 entre 600 - 900 ha e 179 no estrato com áreas maiores que 900 ha. Na Figura 2, demonstra-se que, conforme a área das unidades se eleva, o mesmo ocorre com o número de tratores por unidade produtiva. A área por trator eleva-se com o aumento da área das unidades, indicando que, nas unidades com maior área, a eficiência no uso desses equipamentos pode ser maior.

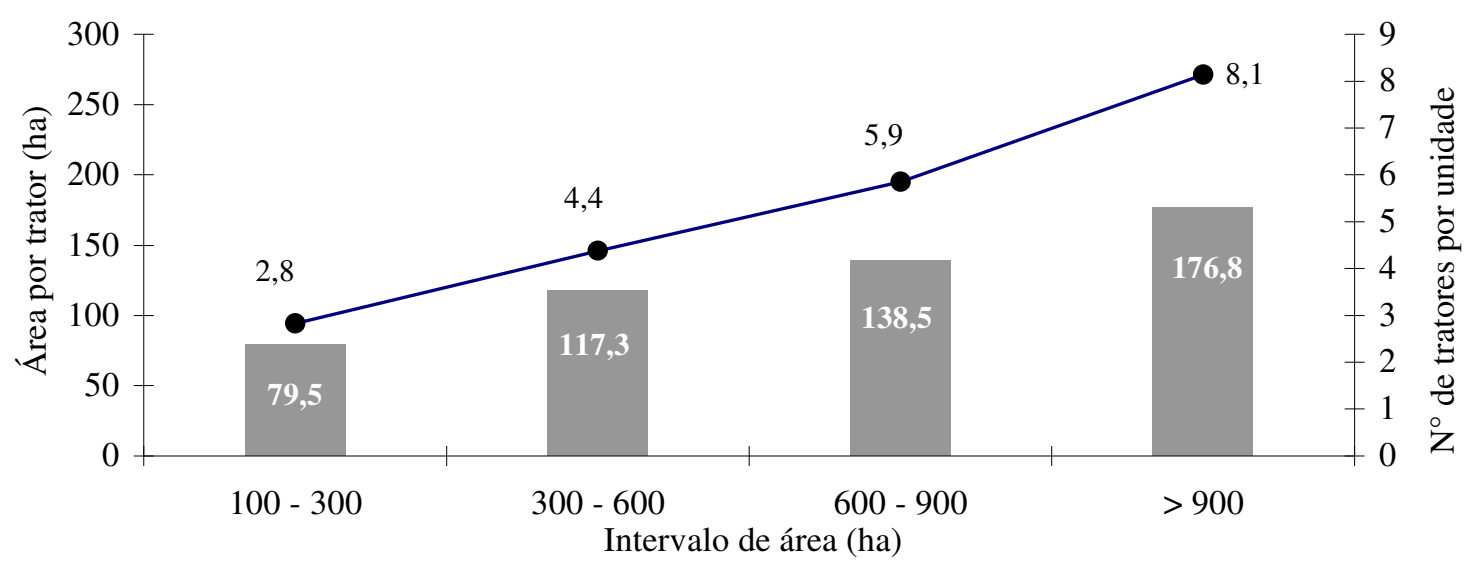

FIGURA 2. Número médio de tratores por unidade e área por trator por unidade.

Os valores de área cultivada por trator demonstraram que, na região, há mais equipamentos por unidade de área comparando-se com os índices do Brasil. A média para todos os estratos é de um trator para cada 128 ha, enquanto a nacional é de um trator para cada 154 ha (ANFAVEA, 2005).

Na Tabela 3, são apresentados os valores de participação dos fabricantes de tratores entre os espécimes levantados. A primeira constatação é que existem equipamentos de quase todos os fabricantes, mas os dois fabricantes com maior participação, MF/AGCO e Ford/New Holland, são responsáveis por 74,3\% do número de tratores, seguido do fabricante John Deere com 11,6\%. 
TABELA 3. Participação dos fabricantes de tratores de acordo com o estrato.

\begin{tabular}{lccccc}
\hline \multirow{2}{*}{ Fabricante } & \multicolumn{5}{c}{ Participação do Fabricante (\%) } \\
\cline { 2 - 6 } & $100-300$ ha & $300-600$ ha & $600-900$ ha & $>900$ ha & Média \\
\hline Massey Ferguson/AGCO & 47,6 & 46,2 & 38,9 & 43,0 & 44,2 \\
Ford/New Holland & 34,1 & 31,6 & 26,7 & 27,4 & 30,1 \\
John Deere & 7,9 & 12,9 & 16,8 & 10,1 & 11,6 \\
Valmet/Valtra & 7,3 & 6,4 & 13,0 & 5,0 & 7,6 \\
Case & 1,2 & 2,3 & 1,5 & 10,6 & 4,2 \\
CBT & 1,8 & 0,0 & 1,5 & 2,8 & 1,6 \\
Agrale & 0,0 & 0,6 & 1,5 & 1,1 & 0,8 \\
\hline
\end{tabular}

Nota-se que, no menor estrato, a variação da participação de fabricantes foi menor que nos demais e que os equipamentos dos fabricantes John Deere e Case foram mais frequientes entre os três maiores estratos. Esses valores podem refletir as estratégias de mercado desses fabricantes que buscam determinado tipo de cliente para seus produtos.

Com relação às características construtivas, a maior parte dos tratores ainda não possui cabine, sendo esse opcional empregado em apenas $23 \%$ dos tratores do estrato em que está mais presente. O tipo de acoplamento mais utilizado é a barra de tração, e o uso de pneus radiais ainda está pouco difundido, havendo menos de $10 \%$ dos tratores utilizando esse tipo de pneus. Constatou-se que, nos últimos 30 anos, a potência dos tratores adquiridos pelos produtores da região aumentou mais de $100 \%$, passando de $40 \mathrm{~kW}$ para $81 \mathrm{~kW}$ (Figura 3).

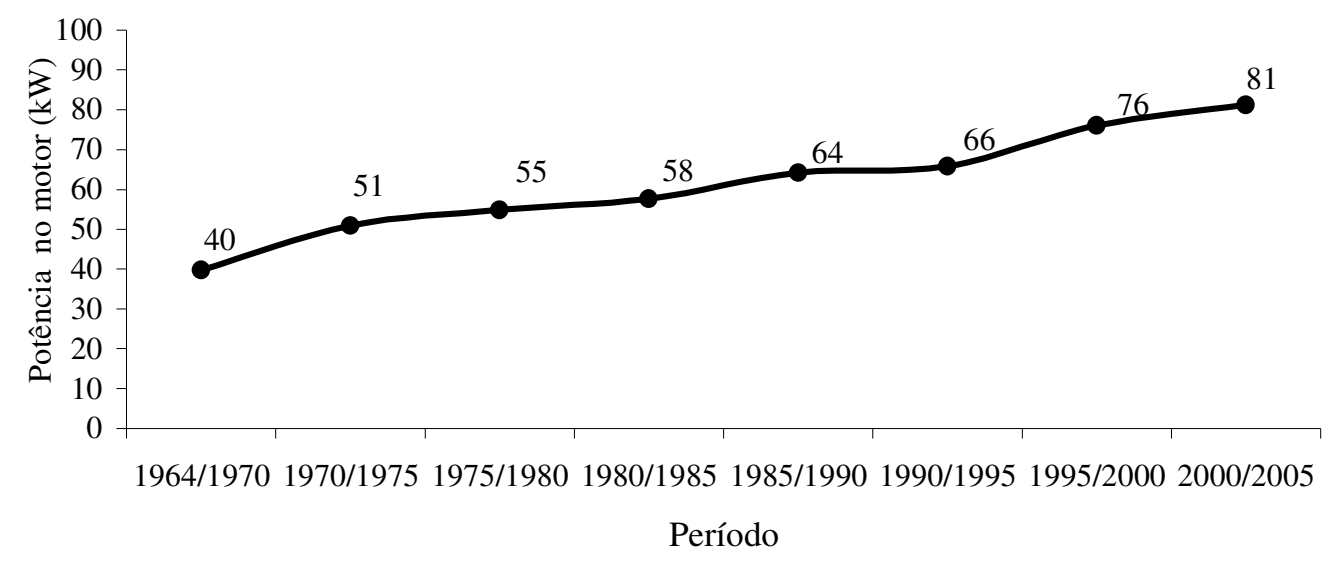

FIGURA 3. Potência média dos tratores conforme o período de fabricação.

Os valores médios de potência por trator, potência por área, idade e intensidade de uso são apresentados na Tabela 5 e demonstram que as unidades com maior área possuem menor potência média por área e que a idade média e a intensidade de uso foram semelhantes.

TABELA 4. Potência, idade e intensidade de uso de tratores.

\begin{tabular}{lcccc}
\hline \multicolumn{1}{c}{ Parâmetros } & \multicolumn{3}{c}{ Intervalo de Área (ha) } \\
\cline { 2 - 5 } & $100-300$ & $300-600$ & $600-900$ & $>900$ \\
\hline Potência média por trator $(\mathrm{kW})$ & 66,80 & 70,70 & 75,90 & 77,80 \\
Potência média por área $\left(\mathrm{kW} \mathrm{ha}^{-1}\right)$ & 0,99 & 0,68 & 0,60 & 0,46 \\
Idade média (anos) & 11,20 & 9,40 & 10,80 & 10,60 \\
Intensidade de uso (horas ano $\left.^{-1}\right)$ & 668 & 725 & 752 & 759 \\
\hline
\end{tabular}

No caso das semeadoras, foram coletadas informações de 371 equipamentos, sendo 235 semeadoras de precisão, 95 semeadoras de fluxo contínuo e 41 semeadoras múltiplas. 
O mecanismo sulcador para a colocação de fertilizantes nas culturas de verão variou, havendo predomínio do mecanismo do tipo disco duplo no caso da soja. Para o milho e o feijão, predominou a haste, seja ela do tipo guilhotina, seja facão.

Houve variação na participação dos mecanismos dosadores de sementes em função do estrato, sendo o mecanismo do tipo pneumático mais presente nos dois estratos maiores e há predominância do mecanismo do tipo disco horizontal em todos os estratos (Tabela 5). No caso das semeadoras de fluxo contínuo e múltiplas, utilizadas na semeadura das culturas de inverno, o mecanismo dosador de sementes do tipo rotor acanalado é utilizado 94\% das vezes; no restante, o mecanismo dosador é do tipo rosca sem fim.

TABELA 5. Participação por estrato dos tipos de mecanismos dosadores de sementes para semeadura das culturas principais.

\begin{tabular}{lcccc}
\hline \multirow{2}{*}{ Mecanismo } & \multicolumn{4}{c}{ Participação (\%) } \\
\cline { 2 - 5 } & $100-300$ ha & $300-600$ ha & $600-900$ ha & $>900$ ha \\
\hline Disco horizontal & 93,0 & 84,1 & 75,1 & 71,5 \\
Pneumático & 4,9 & 15,3 & 22,1 & 24,4 \\
Disco vertical & 1,6 & 0,0 & 2,2 & 4,1 \\
Outro & 0,5 & 0,6 & 0,7 & 0,0 \\
\hline
\end{tabular}

Na Tabela 6, são apresentados os resultados de idade das semeadoras, de acordo com o seu tipo e o estrato considerado. Por serem utilizadas durante as duas safras, as semeadoras múltiplas apresentam desgaste superior às demais, sendo um dos fatores determinantes para que sua idade média seja de 4,7 anos, enquanto, nas de precisão, é de 8,7 anos e, nas de fluxo contínuo, de 9,3 anos. Outro fator é que elas são mais recentes, disponíveis no mercado a partir de 1992-1993.

As semeadoras de precisão e de fluxo contínuo encontradas no estrato de menor área são mais velhas, o que pode ser indicativo de que esses equipamentos são menos utilizados ou de que os produtores estão sem capital para efetuar a troca.

TABELA 6. Idade das semeadoras em função do seu tipo e do estrato considerado.

\begin{tabular}{lcccc}
\hline \multirow{2}{*}{\multicolumn{1}{c}{ Tipo de Semeadora }} & \multicolumn{4}{c}{ Idade Média das Semeadoras (anos) } \\
\cline { 2 - 5 } & $100-300$ ha & $300-600$ ha & $600-900$ ha & $>900$ ha \\
\cline { 2 - 5 } & 10,4 & 8,6 & 8,6 & 7,4 \\
Semeadoras de precisão & 14,9 & 7,2 & 8,7 & 6,2 \\
Semeadoras de fluxo contínuo & 5,1 & 3,3 & 5,1 & 5,3 \\
Semeadoras múltiplas & \multicolumn{4}{c}{. }
\end{tabular}

Conforme pode ser visto na Tabela 7 , as velocidades de deslocamento para as culturas de soja, milho e feijão concentraram-se em faixas inferiores àquelas encontradas na semeadura de trigo e aveia-preta. A cultura do milho foi a que apresentou a maior concentração da faixa de velocidade de deslocamento, sendo que, em 81,3\% das vezes, as semeadoras empregadas se deslocaram em velocidades entre 4 e $6 \mathrm{~km} \mathrm{~h}^{-1}$. Dentre as culturas principais, a soja foi a que apresentou maior variação nas faixas de velocidade de deslocamento, com $6,5 \%$ dos equipamentos operando entre 8 e $10 \mathrm{~km} \mathrm{~h}^{-1}$. Mais de $50 \%$ dos equipamentos destinados à semeadura de aveiapreta e trigo apresentaram velocidade de deslocamento superior a $6 \mathrm{~km} \mathrm{~h}^{-1}$ e apenas $1,7 \%$ entre 2 $4 \mathrm{~km} \mathrm{~h}^{-1}$.

As potências disponíveis por linha de semeadura são apresentadas na Figura 4 para as culturas de verão e inverno. Os valores diferem de acordo com a cultura, sendo o maior valor encontrado para a cultura do milho, que utiliza mecanismos sulcadores para fertilizantes do tipo haste. A média de potência utilizada por linha foi de $15,5 \mathrm{~kW} ; 9,2 \mathrm{~kW} ; 9,2 \mathrm{~kW} ; 4,1 \mathrm{~kW}$ e 4,0 kW para as culturas de milho, soja, feijão, trigo e aveia-preta, respectivamente. 
TABELA 7. Faixas de velocidade de deslocamento durante a operação entre os espécimes levantados para semeadura das culturas.

\begin{tabular}{lcccc}
\hline \multirow{2}{*}{ Cultura } & \multicolumn{3}{c}{ Participação das Velocidades de Deslocamento (\%) } \\
\cline { 2 - 5 } & $2-4 \mathrm{~km} \mathrm{~h}^{-1}$ & $4-6 \mathrm{~km} \mathrm{~h}^{-1}$ & $6-8 \mathrm{~km} \mathrm{~h}^{-1}$ & $8-10 \mathrm{~km} \mathrm{~h}^{-1}$ \\
\hline Soja & 1,2 & 65,6 & 26,7 & 6,5 \\
Milho & 8,9 & 81,3 & 9,4 & 0,4 \\
Feijão & 8,8 & 67,4 & 19,2 & 4,7 \\
Trigo & 1,7 & 44,3 & 40,9 & 13,0 \\
Aveia-preta & 1,6 & 38,7 & 41,9 & 17,7 \\
\hline
\end{tabular}

Com relação aos pulverizadores, foram coletadas informações de 242 equipamentos. Em termos gerais, predominam os equipamentos de arrasto, com um eixo $(70,4 \%)$, tanque de $2.000 \mathrm{~L}$ (73,4\%), barras com comprimento de $18 \mathrm{~m}(78,6 \%)$ e 84,4\% não possuem assistência de ar. Os pulverizadores acoplados ao engate de três pontos predominam no menor estrato.

O número de pulverizadores, comprimento de barra total (valor médio da soma dos comprimentos de barra dos pulverizadores encontrados nas unidades), potência total dedicada (aquela disponível nas fontes de potência empregadas com os pulverizadores) e área cultivada por metro de barra aumentaram conforme se elevou o tamanho da área (Tabela 8).

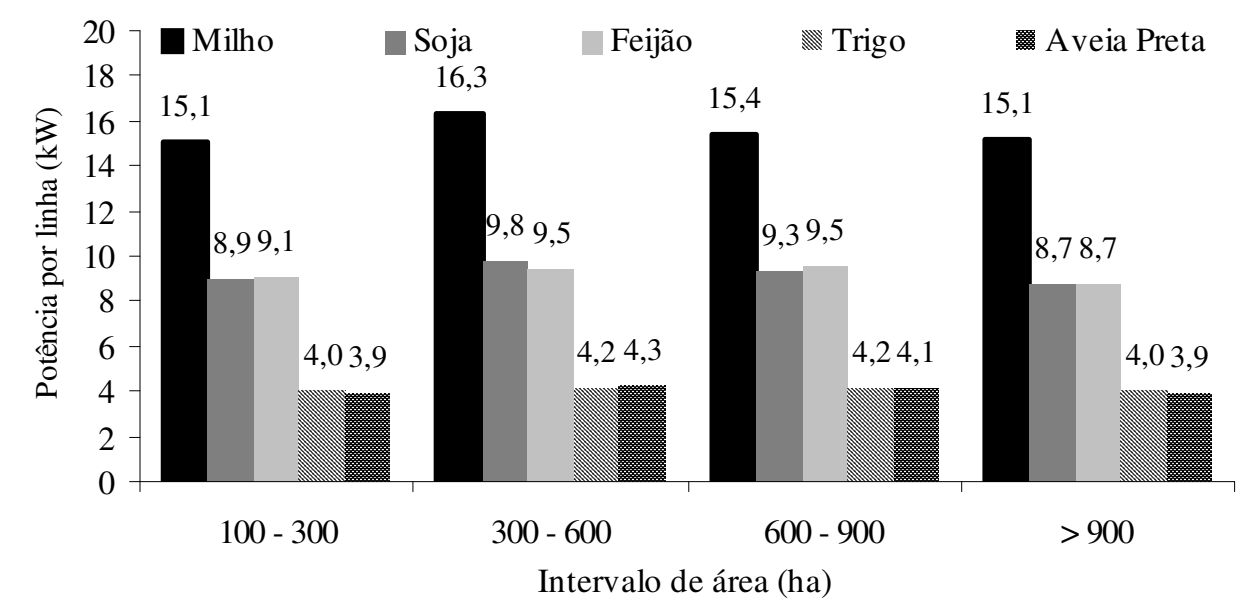

FIGURA 4. Potência por linha de semeadura em função da cultura e do estrato.

Para cada hectare cultivado, é utilizado aproximadamente um terço da potência e cobre-se área três vezes maior por metro de barra do pulverizador comparando-se o estrato de maior área ao de menor. A potência utilizada com os equipamentos para pulverização aumentou com a área.

TABELA 8. Indicadores operacionais para a operação de pulverização.

\begin{tabular}{lccccc}
\hline \multicolumn{1}{c}{ Indicador } & \multicolumn{5}{c}{ Intervalo de área } \\
\cline { 2 - 6 } & $100-300$ ha & $300-600$ ha & $600-900$ ha & $>900$ ha & Média \\
\hline Número de pulverizadores & 1,20 & 1,60 & 2,00 & 2,50 & 1,80 \\
Comprimento de barra $(\mathrm{m})$ & 20,50 & 27,80 & 35,80 & 47,40 & 32,90 \\
Potência por metro de barra $(\mathrm{kW})$ & 3,70 & 3,50 & 3,50 & 3,50 & 3,50 \\
Potência dedicada $(\mathrm{kW})$ & 76 & 98 & 124 & 164 & 115 \\
Potência por área $\left(\mathrm{kW} \mathrm{ha}{ }^{-1}\right)$ & 0,39 & 0,22 & 0,17 & 0,13 & 0,23 \\
Área por metro de barra (ha) & 10,60 & 19,30 & 22,90 & 30,20 & 20,70 \\
\hline
\end{tabular}

Grande parte dos equipamentos apresentou velocidades de deslocamento entre 4 e $8 \mathrm{~km} \mathrm{~h}^{-1}$, e as velocidades maiores foram mais freqüentes nos estratos com maiores áreas. Os volumes de pulverização adotados variaram, mas na maior parte das vezes não excederam $140 \mathrm{~L} \mathrm{ha}^{-1}$. O ajuste do volume de pulverização é realizado em $59,6 \%$ dos equipamentos, enquanto $40,4 \%$ deles 
utilizam o mesmo volume, independentemente do tipo de aplicação, e a maior parte $(72,8 \%)$ tem as pontas trocadas no intervalo de dois anos ou menos. Constatou-se, também, que entre as unidades onde existiam equipamentos com assistência de ar na barra, 80,0\% do total utilizava o sistema, independentemente da condição de aplicação, e 20,0\% apenas quando era necessário. Outro aspecto de interesse é que apenas $24,4 \%$ dos equipamentos utilizados na operação de pulverização possuíam cabines, sejam eles tratores utilizados como fonte de potência para os pulverizadores, sejam equipamentos autopropelidos.

Com relação à idade, o equipamento mais velho tinha 26 anos, e o mais novo, um ano. A idade média dos equipamentos levantados foi de 7,3 anos. Nos estratos, a idade foi de 7,8 anos, 7,4 anos, 6,6 anos e 6,1 anos para 100-300 ha, 300-600 ha, 600-900 ha e maior do que 900 ha, respectivamente. Quanto maior a área, menor a idade média, o que pode significar que os equipamentos das unidades maiores são trocados com maior frequiência, provavelmente pelo maior uso.

Para as colhedoras, foram obtidos dados referentes a 199 equipamentos autopropelidos e, na Figura 5, são apresentados os dados referentes à presença de colhedoras nas propriedades. Para o menor estrato, $73,7 \%$ das unidades possuem o equipamento e, para o estrato de maior área, $100 \%$ das unidades têm uma máquina.

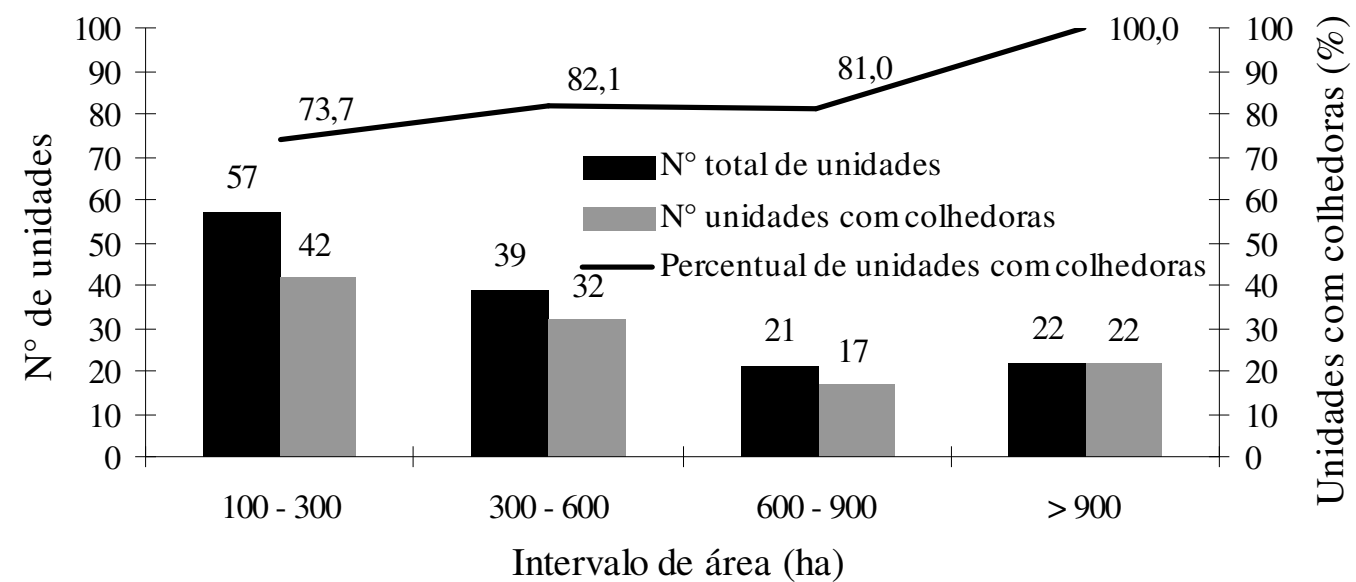

FIGURA 5. Número de unidades participantes, número e percentual das unidades que possuem colhedoras.

O fabricante New Holland apresentou a maior participação, seguido pelos equipamentos SLC/John Deere e Ideal/Massey Ferguson (Tabela 9). A Case pode ser considerada mais recente no mercado de colhedoras e isso pode explicar menor participação e a idade média dos equipamentos de 3,9 anos. Ideal/Massey Ferguson e New Holland têm equipamentos com as maiores idades médias: 12,0 e 12,7 anos, respectivamente. As máquinas SLC/John Deere têm idade média de 8,2 anos.

TABELA 9. Participação dos fabricantes no total de colhedoras.

\begin{tabular}{lc}
\hline Fabricante & Participação (\%) \\
\hline Ideal/Massey Ferguson & 22,6 \\
SLC/John Deere & 28,1 \\
New Holland & 40,7 \\
Case & 8,5 \\
\hline
\end{tabular}

As dimensões dos equipamentos aumentaram conforme se elevou o tamanho das áreas, não havendo proporcionalidade nesse aumento (Tabela 10). A área colhida por uma colhedora no maior estrato foi 3,4 vezes superior àquela colhida no menor estrato. 
TABELA 10. Indicadores operacionais para a operação de colheita.

\begin{tabular}{lccccc}
\hline \multirow{2}{*}{ Indicador } & \multicolumn{5}{c}{ Estratos (ha) } \\
\cline { 2 - 6 } & $100-300$ & $300-600$ & $600-900$ & $>900$ & Média \\
\hline Largura da plataforma de corte $(\mathrm{m})$ & 5,9 & 8,2 & 12,7 & 16,3 & 10,8 \\
Largura da plataforma espigadora (m) & 4,0 & 5,5 & 7,6 & 8,2 & 6,3 \\
Potência dedicada $(\mathrm{kW})$ & 148 & 196 & 319 & 418 & 270 \\
Potência por área $\left(\mathrm{kW} \mathrm{ha}{ }^{-1}\right)$ & 0,80 & 0,43 & 0,42 & 0,33 & 0,50 \\
Área por colhedora (ha) & 183 & 371 & 414 & 627 & 399 \\
\hline
\end{tabular}

Na Figura 6, apresentam-se a variação da potência média das colhedoras e os tamanhos das plataformas, de corte e espigadoras, ao longo dos anos. Em 29 anos, os equipamentos que possuíam potência média de $85 \mathrm{~kW}$ chegaram a $171 \mathrm{~kW}$ ou algo em torno de $3 \mathrm{~kW}$ de aumento de potência ao ano. As plataformas também tiveram seu tamanho aumentado, sendo que as de corte saíram de $4 \mathrm{~m}$ chegando a $6,9 \mathrm{~m}(0,1 \mathrm{~m}$ ao ano), e as espigadoras saíram de $3,4 \mathrm{~m}$ e chegaram a $5,1 \mathrm{~m}$ ( $0,06 \mathrm{~m}$ ao ano). Essas elevações apresentaram tendência mais clara a partir dos equipamentos produzidos há 12 anos e parece ainda não haver se estabilizado.

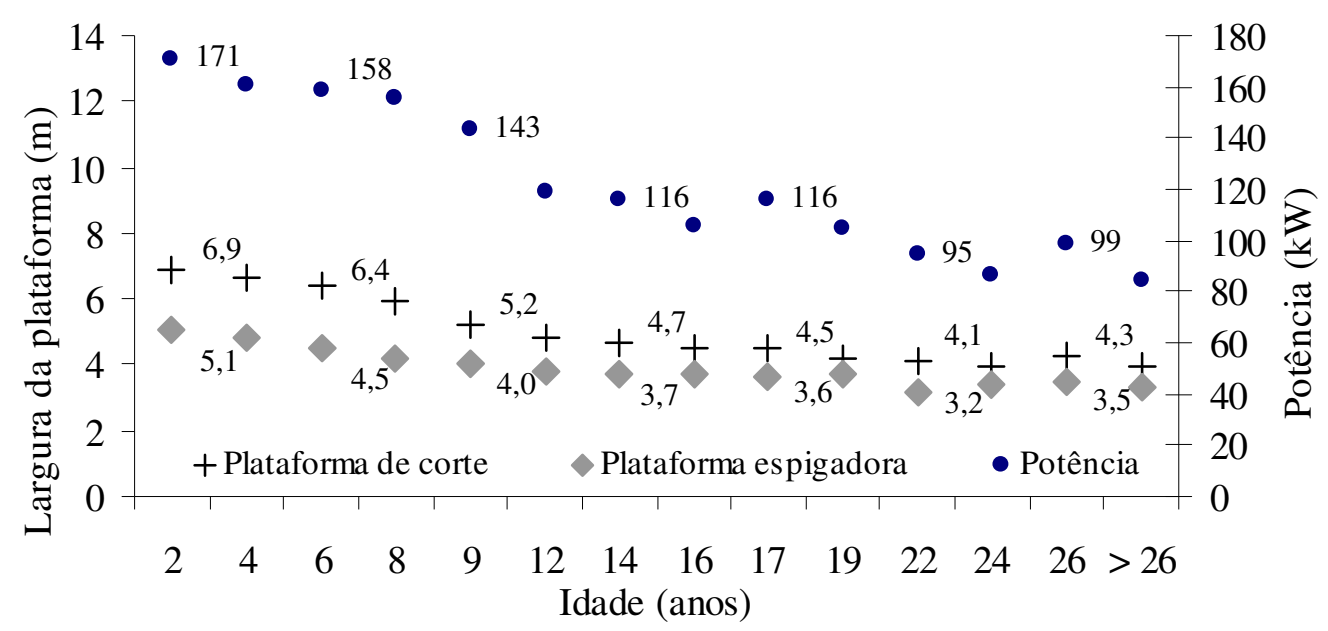

FIGURA 6. Variação do comprimento das plataformas e da potência das colhedoras segundo sua idade.

Uma avaliação geral demonstrou que as unidades do maior estrato apresentaram semeadoras, pulverizadores e colhedoras com idade média inferior àquelas encontradas nas menores unidades, $\mathrm{o}$ que demonstra maior facilidade para a troca ou desgaste mais acentuado devido ao maior uso. Equipamentos com maior idade podem ter maior custo operacional com quebras e necessidade de manutenção freqüente, o que torna sua utilização limitada.

Apesar de numericamente possuir mais equipamentos e potência, as propriedades maiores conseguem produzir mais trabalho por unidade de potência ou equipamento. As unidades menores têm dificuldade em aproveitar o potencial instalado em termos de máquinas. Uma maneira de atenuar esse problema seria a terceirização de serviços de mecanização, ainda pouco difundida na região. A troca de serviços mecanizados entre unidades produtivas por meio da compra de equipamentos em sociedade ou a criação de cooperativas de serviços mecanizados poderia trazer benefícios principalmente às unidades do menor estrato.

\section{CONCLUSÕES}

Houve variação no tamanho das unidades de produção encontradas na região, mas essa variação em tamanho não ocasionou alterações nas culturas empregadas e na produtividade média obtida por elas. 
O tamanho das unidades produtivas influenciou na quantidade de recursos mecanizados disponíveis por área, havendo menos máquinas com o aumento das unidades. A potência por área dos tratores nas unidades menores foi duas vezes maior que a encontrada nas maiores. A idade das semeadoras, pulverizadores e colhedoras foi influenciada pelo tamanho da unidade, sendo maior nas unidades menores.

Houve predominância de alguns fabricantes entre os equipamentos levantados e, conforme o tamanho das unidades aumentou, houve presença de equipamentos mais novos e de itens nos equipamentos que contribuem para o aumento de sua capacidade de trabalho e eficiência.

Obteve-se média de um homem para cada 117,8 ha de área, e o treinamento dessa mão-deobra para operar os equipamentos pode ser considerado insuficiente.

\section{REFERÊNCIAS}

ANDRADE, P.; JENKINS, B.M. Identification of patterns of farm equipment utilization in two agricultural regions of central and northern Mexico. St Joseph: ASAE, 2002. (Paper, 021203)

ANFAVEA. ASSOCIAÇÃO NACIONAL DOS FABRICANTES DE VEÍCULOS AUTOMOTORES. Anuário da indústria automobilística brasileira. 2005. Disponível em: $<$ http://www.anfavea.com.br>. Acesso em: 27 abr. 2006

BORGES FILHO, E. L. O desenvolvimento do plantio direto no Brasil: a conjunção de interesses entre agricultores, indústrias e o estado. 2001. 141 f. Dissertação (Mestrado em Desenvolvimento Econômico, Espaço e Meio Ambiente) - Instituto de Economia, Universidade Estadual de Campinas, Campinas, 2001.

CONAB. COMPANHIA NACIONAL DE ABASTECIMENTO. Custos de produção: safra de verão - safra 2006-2007. Disponível em:

<www.conab.gov.br/download/safra/serieHistorica/soja_br_1998_a_2006.xls>. Acesso em: 19 jun. 2006.

EDWARDS, W. Machinery management: farm machinery selection. Ames: Iowa State University Extension, 2001. 8 p.

IBGE. INSTITUTO BRASILEIRO DE GEOGRAFIA E ESTATÍSTICA. Levantamento sistemático da produção agrícola. Disponível em: <http://www.ibge.gov.br>. Acesso em: 27 abr. 2006.

SCHLOSSER, J.F.; COSTA MACHADO, O.D. da; DEBIASI, H.; PINHEIRO, E.D. Índice de mecanização de propriedades orizícolas no Rio Grande do Sul, Brasil. Ciência Rural, Santa Maria, v.34, n.3, p.791-4, 2004.

VEIGA, C.M. Modelo empírico para a seleção de máquinas agrícolas na cultura da soja considerando a pontualidade na semeadura. 2000. 75 f. Dissertação (Mestrado em Máquinas Agrícolas) - Escola Superior de Agricultura "Luiz de Queiroz", Universidade de São Paulo, Piracicaba, 2000.

WITNEY, B.D. Choosing \& using farm machines. Edinburg: Land Technology, 1988. 412 p. 